\title{
Surveillance of leishmaniasis cases from 15 European centres, 2014 to 2019: a retrospective analysis
}

Gert Van der Auwera ${ }^{1}$, Leigh Davidsson² ${ }^{2}$ Pierre Buffet ${ }^{3}$, Marie-Thérèse Ruf 4,5 , Marina Gramiccia ${ }^{6}$, Stefania Varani ${ }^{7,8}$, Carmen Chicharro $^{9}$, Aldert Bart ${ }^{10}$, Gundel Harms ${ }^{11}$, Peter L. Chiodini ${ }^{12}$, Hanne Brekke ${ }^{13}$, Florence Robert-Gangneux ${ }^{14}$, Sofia Cortes ${ }^{15}$, Jaco J Verweij ${ }^{16}$, Alessandra Scarabello ${ }^{17}$, Sara Karlsson Söbirk ${ }^{18}$, Romain Guéry ${ }^{19}$, Saskia van Henten ${ }^{1}$, Trentina Di Muccio ${ }^{6}$, Elena Carra ${ }^{20}$, Pieter van Thiel ${ }^{10}$, Martin Vandeputte ${ }^{1}$, Valeria Gaspari7 , Johannes Blum ${ }^{4,5}$, LeishMan Surveillance network ${ }^{21}$ 1. 1 Institute of Tropical Medicine, Antwerp, Belgium

2. 2 The Public Health Agency of Sweden, Solna, Sweden

3. 3 Service des maladies infectieuses et tropicales, AP-HP, Hopital Necker, Paris, France

4. 4 Swiss Tropical and Public Health Institute, Basel, Switzerland

5. 5 University of Basel, Basel, Switzerland

6. 6 Istituto Superiore di Sanità, Rome, Italy

7. 7 IRCCS Azienda Ospedaliero-Universitaria di Bologna, Bologna, Italy

8. 8 Department of Experimental, Diagnostic and Specialty Medicine, University of Bologna, Bologna, Italy

9. 9 Instituto de Salud Carlos III, Madrid, Spain

10. Amsterdam University Medical Centre, Amsterdam, the Netherlands

11. Institute of Tropical Medicine and International Health, Charité - Universitätsmedizin Berlin, corporate member of Freie Universität Berlin and Humboldt - Universität zu Berlin, Berlin, Germany

12. Hospital for Tropical Diseases, London, United Kingdom

13. Oslo University Hospital, Oslo, Norway

14. Univ Rennes, CHU Rennes, Inserm, EHESP, Irset - UMR S 1085, Rennes, France

15. Global Health and Tropical Medicine, Instituto de Higiene e Medicina Tropical, Universidade NOVA de Lisboa, Lisbon, Portugal 16. Microvida Laboratory for Medical Microbiology and Immunology, Elisabeth-TweeSteden Hospital, Tilburg, the Netherlands 17. National Institute for Infectious Diseases 'Lazzaro Spallanzani', Rome, Italy

18. Division of Infection Medicine, Lund University, Lund, Sweden

19. Hôpital privé du Confluent, Nantes, France

20. Istituto Zooprofilattico Sperimentale della Lombardia e dell’ Emilia-Romagna ‘Bruno Ubertini’, Brescia, Italy

21. The members of the network are listed under Investigators

Correspondence: Gert Van der Auwera (gvdauwera@itg.be)

Investigators: The investigators are listed at the end of the article.

Citation style for this article:

Van der Auwera Gert, Davidsson Leigh, Buffet Pierre, Ruf Marie-Thérèse, Gramiccia Marina, Varani Stefania, Chicharro Carmen, Bart Aldert, Harms Gundel, Chiodini Peter L., Brekke Hanne, Robert-Gangneux Florence, Cortes Sofia, Verweij Jaco J, Scarabello Alessandra, Karlsson Söbirk Sara, Guéry Romain, van Henten Saskia, Di Muccio Trentina, Carra Elena, van Thiel Pieter, Vandeputte Martin, Gaspari Valeria, Blum Johannes, LeishMan Surveillance network. Surveillance of leishmaniasis cases from 15 European centres, 2014 to 2019: a retrospective analysis. Euro Surveill. 2022;27(4): pii=2002028. https://doi.org/10.2807/1560-7917.

ES.2022.27.4.2002028

Background: Surveillance of human leishmaniasis in Europe is mostly limited to country-specific information from autochthonous infections in the southern part. As at the end of 2021, no integrated analysis has been performed for cases seen across centres in different European countries. Aim: To provide a broad perspective on autochthonous and imported leishmaniasis cases in endemic and non-endemic countries in Europe. Methods: We retrospectively collected records from cutaneous, mucosal and visceral leishmaniasis cases diagnosed in 15 centres between 2014 and 2019. Centres were located in 11 countries: Belgium, France, Germany, Italy, the Netherlands, Norway, Portugal, Spain, Sweden, Switzerland and the United Kingdom. Data on country of infection, reason for travelling, infecting species, age and sex were analysed. Results: We obtained diagnostic files from 1,142 cases, of which $76 \%, 21 \%$ and $3 \%$ had cutaneous, visceral, and mucosal disease, respectively. Of these, $68 \%$ were men, and $32 \%$ women, with the median age of 37 years (range: 0-90) at diagnosis. Visceral leishmaniasis was mainly acquired in Europe (88\%; 167/190), while cutaneous leishmaniasis was primarily imported from outside Europe ( $77 \%$; 575/749). Sixty-two percent of cutaneous leishmaniasis cases from outside Europe were from the Old World, and $38 \%$ from the New World. Geographic species distribution largely confirmed known epidemiology, with notable exceptions. Conclusions: Our study confirms previous reports regarding geographic origin, species, and traveller subgroups importing leishmaniasis into Europe. We demonstrate the importance of pooling species typing data from many centres, even from areas where the aetiology is presumably known, to monitor changing epidemiology.

\section{Introduction}

Kinetoplastid parasites of the genus Leishmania cause a variety of diseases in humans, collectively known as the leishmaniases [1]. Visceral leishmaniasis (VL) is a systemic parasitic infection characterised by fever, weight loss, anaemia, and hepato- and splenomegaly. If not treated, the disease is generally lethal. Cutaneous leishmaniasis (CL) displays different levels of severity, from single benign self-healing lesions to complex clinical presentations with multiple lesions on different 
TABLE 1

Participating European centres of the LeishMan network ${ }^{a}$, country of diagnosis and number of leishmaniasis cases, 2014$2019(\mathrm{n}=15)$

\begin{tabular}{|l|c|c|}
\hline Centres & Country of diagnosis & Number of cases \\
& Belgium & $1,142)$ \\
\hline Institute of Tropical Medicine Antwerp & France & 38 \\
\hline Centre Hospitalier Universitaire de Rennes & France & 128 \\
\hline Necker Pasteur Paris & Germany & 64 \\
\hline Charité-Universitätsmedizin Berlin & Italy & 10 \\
\hline INMI Lazzaro Spallanzani & Italy & 113 \\
\hline Istituto Superiore di Sanità Rome & Italy & 109 \\
\hline University Hospital of Bologna & Netherlands & 86 \\
\hline Amsterdam University Medical Centres & Netherlands & 18 \\
\hline Elisabeth-TweeSteden Hospital Tilburg & Norway & 42 \\
\hline Oslo University Hospital & Portugal & 22 \\
\hline Instituto de Higiene e Medicina tropical & Spain & 86 \\
\hline Instituto de Salud Carlos III & Sweden & 133 \\
\hline Public Health Agency of Sweden & Switzerland & 121 \\
\hline Swiss Tropical and Public Health Institute & United Kingdom & 48 \\
\hline Hospital for Tropical Diseases & \\
\hline
\end{tabular}

INMI: Istituto Nazionale per le Malattie Infettive.

a The European LeishMan network for diagnosis, treatment and surveillance of leishmaniasis in Europe was established in 2010 and currently has 33 affiliated institutes.

body parts that are often difficult to treat successfully. A complication of $\mathrm{CL}$ is mucosal leishmaniasis $(\mathrm{ML})$, affecting mucosal tissues primarily of the nose and mouth, with potential mutilating and stigmatising consequences. ML can manifest either as a primary infection, possibly with concomitant cutaneous lesions, or after a previously resolved cutaneous infection.

Transmission of the parasite occurs through bloodfeeding female sandflies. In Europe, the vector mainly occurs in the southern countries, primarily those of the Mediterranean basin. Several papers have described the epidemiology of endemic leishmaniasis in Europe $[2,3]$. However, analyses on imported leishmaniasis in endemic and non-endemic regions have rarely integrated data from more than a single country $[4,5]$. $L$. infantum and L. tropica are the only species known to be transmitted in Mediterranean Europe, but globally between 15 and 20 Leishmania species are pathogenic to humans [6].

The European LeishMan network was established in 2010, with the aim of sharing leishmaniasis case management data, and harmonising diagnosis and treatment [7]. To reveal epidemiological trends of the recent years (2014-19), we analysed case data from 15 of the 33 centres of the network, all situated in western Europe and Scandinavia. To our knowledge, this is the largest analysis of the leishmaniases in Europe to date, thereby contributing to permanent monitoring of autochthonous and travel-related cases in Europe $[6,8]$, and supplementing surveillance efforts in eastern European countries $[9,10]$.

\section{Methods}

\section{Study setting and period}

Fifteen centres within the European LeishMan network from 11 countries in west and north Europe (Table 1) shared their diagnostic leishmaniasis case data from the period 2014-19 in a common database. Because of the geographic spread of the participating centres, it is highly unlikely that the same patient would have visited more than one centre during the study period, minimising the chances of counting the same case twice. For each case, the following variables were collected: (i) year of diagnosis, (ii) age at time of diagnosis, (iii) sex, (iv) type of disease (CL, ML, VL, or a combination of these), (v) autochthonous or imported (including reason for travel), (vi) probable country of infection, (vii) the species, species complex or subgenus of the parasite and (viii) the genomic target and method that were used for parasite typing.

\section{Age, sex and year of diagnosis}

Because the exact infection date is unknown, the date of sampling for disease confirmation was used. Age and sex were recorded; the age of the patient on this date was recorded as the age at time of diagnosis, which was analysed in periods of 10 years. As the study uses retrospective data, the travel and disease history was not uniformly recorded across centres, but we aimed to collect the first disease episode for every case. We took utmost care to avoid inclusion of relapses from infections dating before 2014, even though this cannot be guaranteed if the patient visited other clinics before consulting one of the centres participating to the study. 
TABLE 2

Taxonomy of the Leishmania genus

\begin{tabular}{|c|c|c|c|}
\hline Genus & Subgenus & Complex & Species \\
\hline \multirow{14}{*}{ Leishmania } & \multirow{7}{*}{ L. (Leishmania) } & \multirow{2}{*}{ L. donovani } & L. donovani \\
\hline & & & L. infantum (syn. L. chagasi in New World) \\
\hline & & L. major & L. major \\
\hline & & \multirow{2}{*}{ L. mexicana } & L. amazonensis (syn. L. garnhami) \\
\hline & & & L. mexicana \\
\hline & & \multirow{2}{*}{ L. tropica } & L. aethiopica \\
\hline & & & L. tropica \\
\hline & \multirow{6}{*}{ L. (Viannia) } & \multirow{2}{*}{ L. braziliensis } & L. braziliensis \\
\hline & & & L. peruviana \\
\hline & & \multirow{2}{*}{ L. guyanensis } & L. guyanensis \\
\hline & & & L. panamensis \\
\hline & & L. lainsoni & L. lainsoni \\
\hline & & L. naiffi & L. naiffi \\
\hline & L. (Enriettii) & L. enriettii & L. siamensis / L. martiniquensis \\
\hline
\end{tabular}

Only species present in the diagnostic records are included [11-13].

For $\mathrm{ML}$, however, some cases are likely a relapse from an earlier CL manifestation, especially those imported from the New World.

\section{Type of disease}

The three main clinical manifestations of a Leishmania infection were discriminated: $\mathrm{VL}, \mathrm{CL}$, and ML. A case was interpreted as ML if mucosal tissue was affected, irrespective of concomitant or earlier cutaneous lesions elsewhere on the body. The same case definitions are used throughout the LeishMan network. The definitions of these main leishmaniasis manifestations are straight-forward, and this study did not stratify according particular sub-categories of $C L$ and $M L$ where classification would be more ambiguous.

\section{Autochthonous versus imported cases}

An autochthonous case was considered as an infection that took place in the country where it was diagnosed. All other cases were considered as imported or travel related, e.g. an infection diagnosed in France but acquired in Spain was considered an imported infection, even though it was acquired in Europe. For imported cases, we further subdivided this category into migrants, tourists, military personnel, and people visiting friends or relatives (VFR). If there was another reason for travelling, or the reason for travelling was not known, the case was categorised as 'Traveller unspecified', to make the distinction with an autochthonous case. The classification 'Unknown' was reserved for those cases without information distinguishing an imported or autochthonous infection.

\section{Country of infection}

The 'country of infection' was defined as the country where the case was most likely infected. Some cases, especially migrants and tourists, often travelled through various endemic regions, so the exact country of infection was impossible to establish. For migrants, we assumed they were infected in their home country unless other countries were mentioned in the diagnostic records. Whenever the exact country of infection was unclear from the medical record, we pragmatically grouped them into the following regions from the Old World: (i) Mediterranean, (ii) Sub-Saharan Africa and (iii) the Middle East including Pakistan, and from the New World: (iv) South America and (v) Middle America (Mexico, Central America and the West Indies). If no information on the source country was available, or patients visited several of the aforementioned regions, the case was categorised as (vi) 'Unknown'.

\section{Species, species complex and subgenus}

The taxonomy of the Leishmania genus as used in this paper is listed in Table 2 [11-13]. Most centres could reliably determine the species complex of the aetiological agent, using a variety of genomic targets and analysis methods. However, typing the exact species within the complex is often more challenging because of the genetic similarity within the complex and/or lack of a clear consensus on species definition [14]. In some cases, the species was determined by a referring centre, in which case the typing method was unknown. When a species was reported, but the method used does not allow reliable discrimination within the complex, only the species complex information was retained. Even though utmost care was taken to ensure correct identification down to the species level, the analysis was primarily limited to the species complex. In some cases, the typing was limited to the subgenus level, only discriminating between L. (Leishmania) and L. (Viannia).

\section{Genomic targets and methods}

Several methods and genome loci were used for genomic typing purposes. These include sequencing, restriction fragment length polymorphism (RFLP) analysis, and/or subgenus-specific PCR of the following: 


\section{FIGURE 1}

Overview of leishmaniasis cases identified by 15 European centres, 2014-2019

\section{A. Cases by sex and disease type $(n=1,135)$}

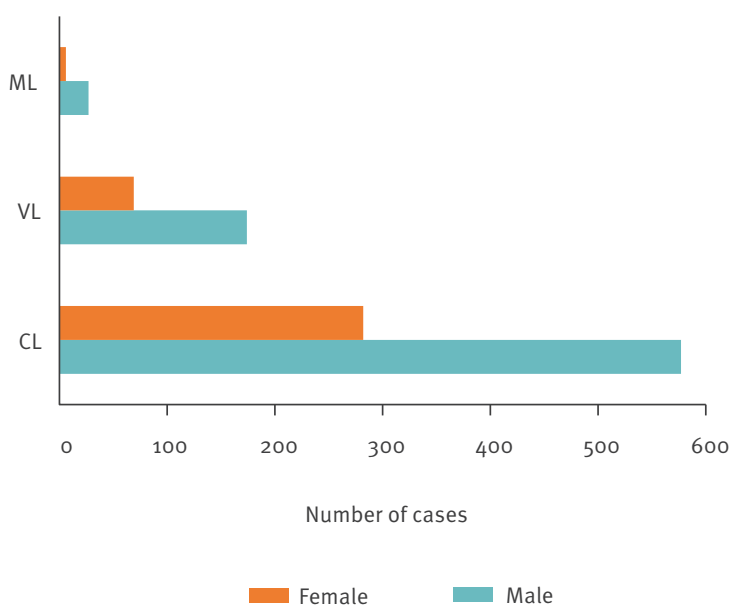

\section{Annual distribution by disease type $(n=1,142)$}

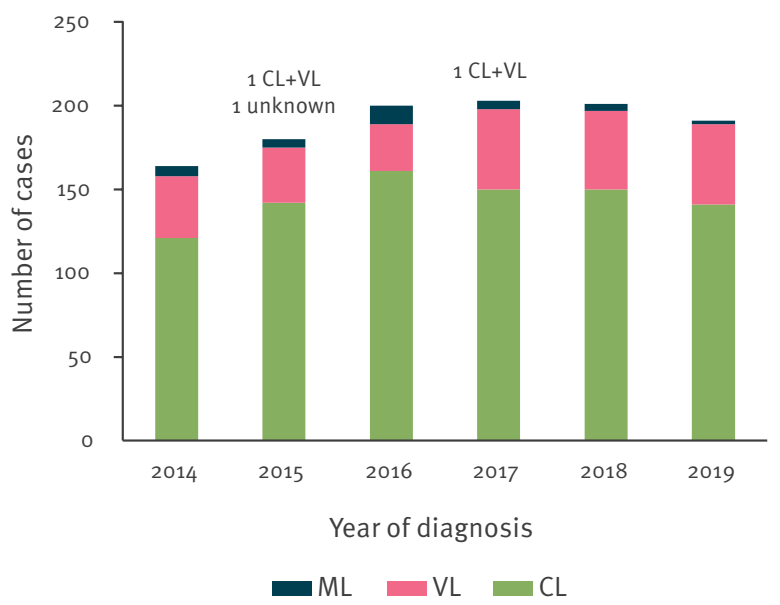

E. Species complexes $(n=1,142)$

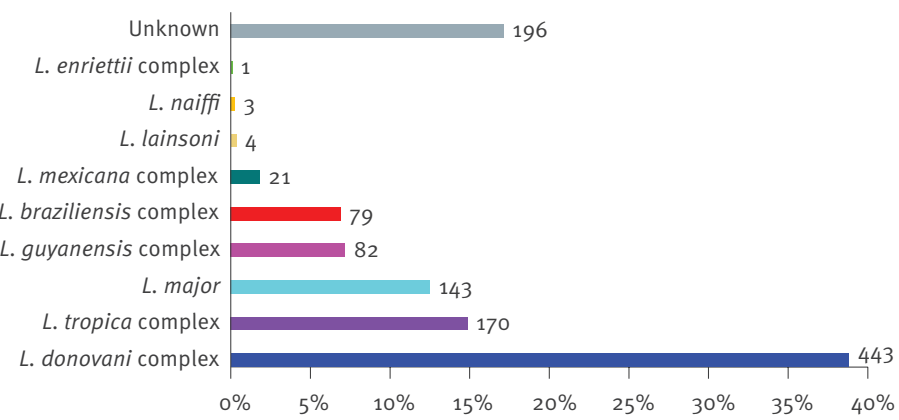

B. Age distribution at diagnosis by disease type $(n=1,122)$

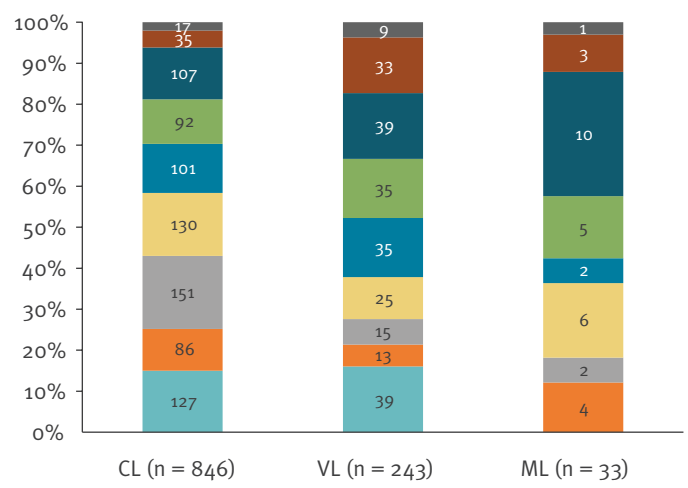

Age range (years)

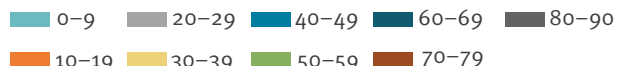

\section{Reason for staying in endemic area $(n=1,142)$}

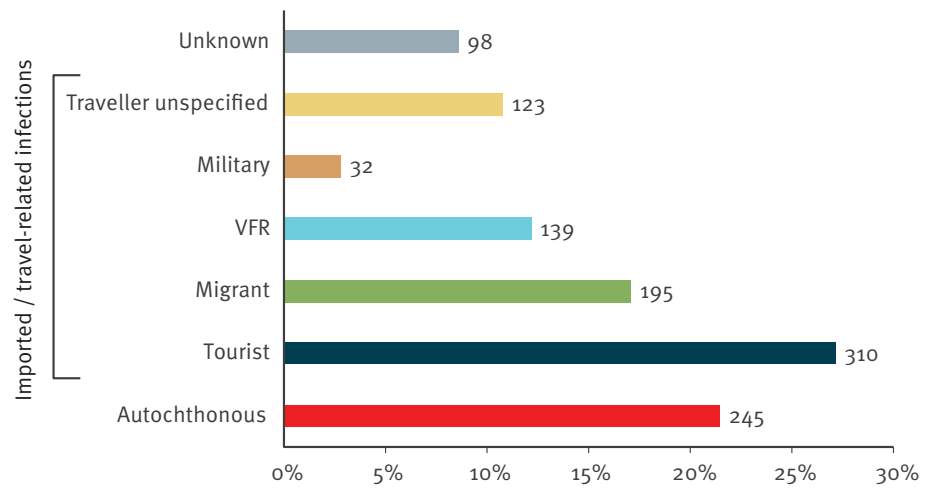

F. Targets used for typing $(n=1,142)$

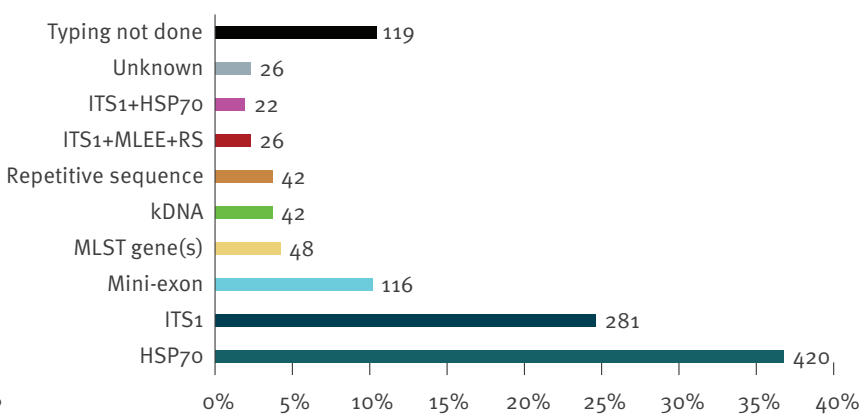

CL: cutaneous leishmaniasis; HSP70: heat-shock protein 70; ITS1: internal transcribed spacer 1 of the rDNA array; kDNA: kinetoplast DNA; ML: mucosal leishmaniasis; MLEE: multilocus enzyme electrophoresis [47]; MLST: multilocus sequence typing; RS: repetitive sequence; VFR: visiting friends or relatives; VL: visceral leishmaniasis.

Panel A and B: Two cases suffering concomitant VL and CL were counted in both categories. Panel B: Total case numbers depicted in each age range box. Panel D: 'Traveller unspecified' are imported cases for which the reason for travelling to an endemic area was unknown. 'Unknown' are either imported or autochthonous infections. Panel E: ‘Unknown' was used where parasite typing was not done or was inconclusive. Panel F: Multilocus enzyme electrophoresis was performed according to reference [47]. 'Unknown' was used where the typing target was not recorded. The $\mathrm{x}$ axis for panels $\mathrm{D}-\mathrm{F}$ shows percentages of all 1,142 records, the numbers on each bar are the actual values. 
heat-shock protein 70 gene (HSP70) [15-17], the internal transcribed spacer 1 of the rDNA locus (ITS1) $[18,19]$, the mini-exon $[19,20]$, multilocus sequence typing (MLST) genes [21], a repetitive sequence [22], and kDNA minicircles [14]. Both the target and method used were registered. Good quality sequences were submitted to GenBank.

\section{Ethical statement}

All data were shared and analysed anonymously in accordance with respective national guidelines. If needed, specific ethical clearance was obtained from the ethical committees or institutional review boards from the respective centres (ethical approval numbers are listed in the Supplementary Material: Ethics statements).

\section{Results}

Of the 1,142 records, more than half of cases were diagnosed in four countries: Italy $(n=232)$, France $(n=166)$, Sweden $(n=133)$, and Belgium $(n=124)$ (Table 1). Because some records had missing data, denominators mentioned throughout the text count only those records where data were available. Of all cases, $68 \%$ $(776 / 1,133)$ were males and $32 \%(357 / 1,133)$ were females. Autochthonous infections represented $23 \%$ (245/1,044) of cases, while $77 \%(799 / 1,044)$ were travel-related. The median age at diagnosis was 37 years (range: $0-90)$, and 15\% $(166 / 1,120)$ were younger than 10 years. Numbers are stratified according to disease (Figures $1 \mathrm{~A}$ and $1 \mathrm{~B}$ ).

The distribution per annum during 2014-19 shows that the majority of cases were $\mathrm{CL}(76 \% ; n=865)$, followed by VL $(21 \% ; n=241)$; only $3 \%(n=33)$ showed mucosal involvement (Figure $1 \mathrm{C}$ ). Two cases had concomitant $C L$ and $V L$. In 1,044 cases, the reason for staying in an endemic area was classified (Figure 1D), with the majority being tourists (27\%). The parasite was typed in 946 cases, most of which (47\%) were infected with the $L$. donovani complex (Figure $1 \mathrm{E}$ ). In 997 cases, the genomic target used for typing was recorded (Figure $1 \mathrm{~F}$ ), and $75 \%$ of these included the heat-shock protein 70 and/or internal transcribed spacer 1 of the rRNA gene array. In all samples typed with a recorded method $(n=950)$, sequence analysis was used in $74 \%$, RFLP in $22 \%$, and a subgenus-specific PCR in $4 \%$.

The full dataset including GenBank accession can be downloaded and explored interactively in the MicroReact platform (https://microreact.org/project/ leishman-2014-2019) [23].

\section{Country of infection}

The probable country of infection was determined for 946 of $1,142(83 \%)$ cases. These countries were pragmatically grouped into the endemic regions (Figure 2 ). Of the remaining 196 cases, 140 visited several of these endemic regions, and hence the origin of infection was impossible to establish. Finally, 56 cases visited different countries from the same endemic region, and for these the endemic region rather than the exact country is reported. The species complexes that were found in each of the regions, as well as the total caseload, are shown (Figure 2).

Species from the $L$. donovani complex were found both in the New and Old World. Most of these were $L$. infantum (in the New World, also known as L. chagasi), while $L$. donovani was identified only from the Horn of Africa and Afghanistan. L. tropica was imported from northern Africa and the Middle East, with one case from Eritrea, while L. aethiopica was identified only from Ethiopia. L. major had a broad distribution in the Middle East and in Africa north of the equator. The L. braziliensis species complex was imported to Europe from Central and South America, with $L$. peruviana identified in one case from Peru. The $L$. guyanensis complex showed the same distribution, with $L$. panamensis originating only from the pacific coastline. L. naiffi was found in Belize and French Guiana. The L. lainsoni cases originated from Brazil and Peru. The L. mexicana complex was identified from several Latin American countries, with a marked dichotomy between L. mexicana in Middle America and $L$. amazonensis in South America. The L. (enriettii) species complex was identified in one case that visited several leishmaniasis endemic zones and could have been infected in either Guyana, Ghana, or Grenada in the Caribbean area.

\section{Subgroup results}

We examined relevant trends for different sub-categories of the variables (Figure 3). VL was primarily acquired within European countries (Figure $3 \mathrm{~A}$ ). Of the $190 \mathrm{VL}$ cases, $65 \%$ were autochthonous infections and $23 \%$ originated from travels to southern European countries (mainly Spain) and the Balkan peninsula, while only $12 \%$ were infections acquired in other countries. In contrast, $77 \%$ of the $750 \mathrm{CL}$ infections were imported from other countries, and thus only $23 \%$ were from south Europe and the Balkan region (Figure $3 \mathrm{~A}$ ). For the $27 \mathrm{ML}$ cases, the difference in origin was not pronounced (Figure $3 \mathrm{~A}$ ).

Of the 245 autochthonous cases, 212 were typed and found to be infected with a species from the $L$. donovani complex (Figure 3B), i.e. L. infantum in the 190 cases for which the species was determined. Five percent of these infections caused ML, the rest was equally divided over $\mathrm{VL}$ and $C L$ pathologies. With the exception of one $L$. major infection causing $C L$, the same pattern was seen in travellers who were infected in southern Europe or the Balkan countries, but with slightly more CL than VL cases (Figure 3B). In this population, L. infantum was identified as the only species of the $L$. donovani complex.

Of the $576 \mathrm{CL}$ cases with known origin imported into Europe, $62 \%$ and $38 \%$ were from the Old and New World, respectively. In the Old World (Figure 3C), mainly migrants contracted $\mathrm{CL}$ in Syria, Afghanistan, the 
Probable region of infection and Leishmania species complex of leishmaniasis cases identified by 15 European centres, $2014-2019(\mathrm{n}=1,142)$

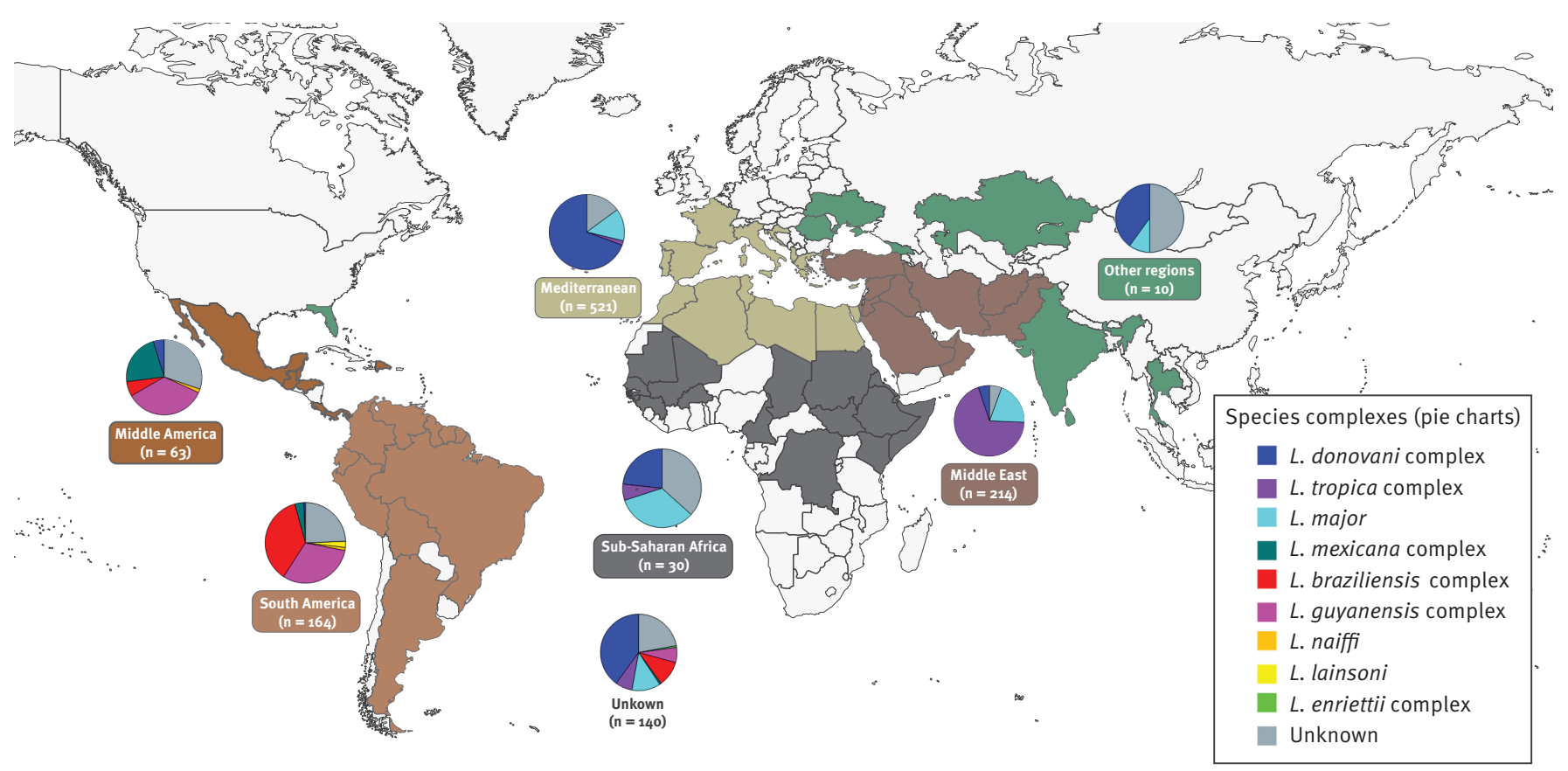

Each region is shown in a different colour (boxes) and the countries within each region where leishmaniasis cases were diagnosed are indicated on the map. The corresponding pie chart represents the Leishmania species complexes (Table 2) that were identified within each region (see legend). The number below the region name is the total number of cases represented in the respective pie chart. The category 'Other regions' (green) includes the countries or states not included in one of the five natural endemic regions. The pie chart 'Unknown' represents cases for which the origin of infection could not be linked to any of the six regions, either because the case visited several regions, or travel history was not known. These data can be interactively explored in detail at country level from the MicroReact platform (https://microreact.org/project/leishman-2014-2019).

Middle East in general, and Pakistan. VFR contracted $\mathrm{CL}$ in Morocco, Tunisia, and Algeria. In Israel, mainly tourists were infected and imported cases to Europe. For the New World (Figure $3 \mathrm{C}$ ), tourists imported 53\% of the $\mathrm{CL}$ cases to Europe, mostly from Peru, Costa Rica, Brazil, Bolivia, and Mexico. Travellers for whom the reason of travelling was not documented imported another $28 \%$ of cases, and several of these were probably tourists as well. Most infections from French Guiana and Belize were seen in military personnel.

All species complexes caused CL, except for the single L. enriettii species complex, which caused VL. As mentioned previously, L. infantum was the only species found to cause VL and $M L$ in European-acquired infections. The parasite was typed to the species level in only $19 \mathrm{VL}$ and $\mathrm{ML}$ cases infected outside Europe (Figure $3 C$ ). In these cases, VL was caused by L. donovani, L. infantum and L. siamensis or L. martiniquensis, while $L$. braziliensis, L. tropica, L. guyanensis and $L$. infantum caused ML.

\section{Discussion}

We examined trends in autochthonous and imported leishmaniasis cases recorded by 15 centres throughout
Europe between 2014-19 with respect to disease, age, sex, region/country of origin, species, and reason for travelling. Our analyses lend further support to previously described trends, with a specific focus on the European territory and integration of data from many centres in non-endemic countries. This adds to earlier reports describing a global picture of travellers, or focussing on European endemic countries only.

We observed a difference in age distribution between $\mathrm{VL}$ and $\mathrm{CL}$, which is linked to the respective patient populations. Because $\mathrm{CL}$ is primarily imported into Europe, it tends to affect young active travellers: infant and adolescent migrants, military personnel, and tourists. In particular, young people who engage in activities with high risk of vector contact, e.g. backpacking and sleeping outdoors or in tents, are at increased risk. Further, children below 10 years of age can easily become infected when travelling to endemic regions, e.g. visiting friends or family, which can be explained by their immature immune system in combination with vector contact while playing outdoors. In VL, infants, children ( 10 years) and elderly people (>60 years) were most often affected, which could be explained by the fact that VL is primarily an autochthonous disease 
caused by L. infantum, affecting people with a compromised immunity [24].

We observed that twice as many cases were male as opposed to female, both in VL and $C L$, which can be explained by two factors. First, in many parts of the world, males are more often engaged in outdoor activities and behaviour that could render them more prone to vector contact and thus infection and, second, females are less susceptible to severe disease [25].

We confirmed the findings of a literature review by Mansueto et al. [26] showing that VL cases diagnosed in Europe primarily originate from European endemic countries, and that cases are rarely imported from nonEuropean regions. Also, we found $L$. infantum as the only causative species, confirming other reports [3]. The vast majority (>60\%) of cases, both with $\mathrm{VL}$ and $\mathrm{CL}$, who were travellers to southern Europe were infected in Spain, which is in line with findings by Ehehalt et al. examining cases in European tourists during the period 2000-12 [4]. This reflects the popularity of the country as a holiday destination [27]. Boggild et al. [5] analysed $955 \mathrm{CL}$ and $\mathrm{ML}$ cases in migrants and travellers reported in the global GeoSentinel surveillance network for the period 1997-2017, and they too identified Spain as one of the main source countries of leishmaniasis in travellers. Regarding domestic $C L$, a recent analysis from Greece on the number of $C L$ Vs VL cases during the period $2004-18$ reported that only $2.7 \%$ (24/886) of domestic infections were CL [10]. This is a huge contrast with our analysis, where $55 \%(174 / 316)$ were $\mathrm{CL}$. The reason for the difference is unclear.

Most CL cases were imported from outside the European territory. Boggild et al. found that Old World $\mathrm{CL}$ is imported primarily by migrants and VFR [5]. They identified Syria and Afghanistan as the main source countries for migrants who acquired $C L$, which is in line with our findings. This is not surprising, as migrants from these areas often emigrate to Europe [28]. This illustrates that a secondary effect of human migration from conflict zones - apart from the direct humanitarian crisis - is an increased risk of importing new pathogens into Europe. Only $10 \%$ of travel-related $\mathrm{CL}$ or $\mathrm{ML}$ cases were migrants according to Boggild et al. [5], while this number was $25 \%$ in our analysis. This can be attributed to the heavy caseload from Syrian and Afghan refugees in recent years. In both our analysis and that by Boggild et al., Tunisia, Morocco and Algeria are in the top five countries of acquisition for VFR, and both found that mainly tourists were infected in Israel. In the Boggild et al. study [5], the three New World countries where most travellers acquired $C L$ or $M L$ were Bolivia, Costa Rica and Peru. Together with French Guiana and Brazil, these three countries made up the top five in our analysis; and as in [5] primarily tourists were infected. Of note, our findings show that Brazil, which covers half the area of the South American continent, represented only $8 \%$ of all New World CL cases.
Our analysis shows that among travellers, tourists may be at greatest risk for developing $M L$ or $V L$, as $65 \%$ (166/254) were infected with species from the L. donovani or L. braziliensis complex. Where the species were identified, the latter were all $L$. braziliensis except for a single case of $L$. peruviana. The $L$. donovani complex species can cause both ML and VL, while L. braziliensis can lead to $M L$ [6]. The risk of $M L$ in tourists travelling to the New World was also identified in [5]. In addition, tourists and military personnel were infected with species from the L. guyanensis complex, occasionally causing ML as well [5]. However, only 5\% (10/200) of tourists theoretically at risk based on these infecting species actually presented ML, and none (0/20) of the military personnel. From the Old World, we identified two migrants with $\mathrm{ML}$ in a total 124 infected with $L$. tropica, again indicating the limited risk. In contrast, of the 122 tourists infected with species from the $L$. donovani complex, 49 (40\%) developed VL, underscoring a high risk.

Some of our typing records presented unexpected results in the context of the known epidemiology of species and disease distribution $[29,30]$. Cases of $L$. infantum were reported from Cameroon, Guinea, Kenya, India, the Dominican Republic, and the United States (US). In Cameroon and Guinea, L. major is the known aetiological agent of CL [29]. The L. donovani complex was previously isolated from a sandfly vector in Cameroon [31], but this is the first report of a $C L$ and $M L$ case. The case from Guinea had VL and, in this area, humans have been found to be seropositive both for L. donovani and L. major [32]. The few cases we identified provide further support to the spread of $L$. infantum in West Africa, as was previously evidenced from human VL and $C L$ in various countries, the presence of and parasite isolation from the vector, and identification of leishmaniasis in dogs, typically considered the species' reservoir [33]. In Kenya, different forms of $C L$ were previously reported from $L$. major, L. tropica, and L. aethiopica, while VL is caused by $L$. donovani [29]. We detected a CL case caused by $L$. infantum, which is unique for East Africa. Even though $L$. infantum had been described based on multilocus microsatellite data, further analysis revealed they were all $L$. donovani $[34,35]$. Equally unique is the single VL case we report from an $L$. infantum infection acquired in India, while L. donovani is the causative agent in the country [29]. Evidently, no conclusions can be drawn from these single incidents, as we cannot rule out that the cases were infected in another country, and species typing was based on a single genome locus, i.e. a partial HSP7O sequence. Of note, microsatellite and whole genome analyses identified a separate clade in the L. donovani species complex, consisting of strains from Kenya and a subset of India and Ethiopia $[34,36]$. At present, we cannot exclude that these strains have an HSP70 sequence that would incorrectly classify them as L. infantum. Finally, autochthonous $C L$ from $L$. infantum has never been documented in the Dominican Republic or the US, where two tourists were 


\section{FIGURE 3}

Stratification according to geographic origin, species complexes and populations of leishmaniasis cases from 15 European centres, 2014-2019

\section{A. Disease types according to populations}

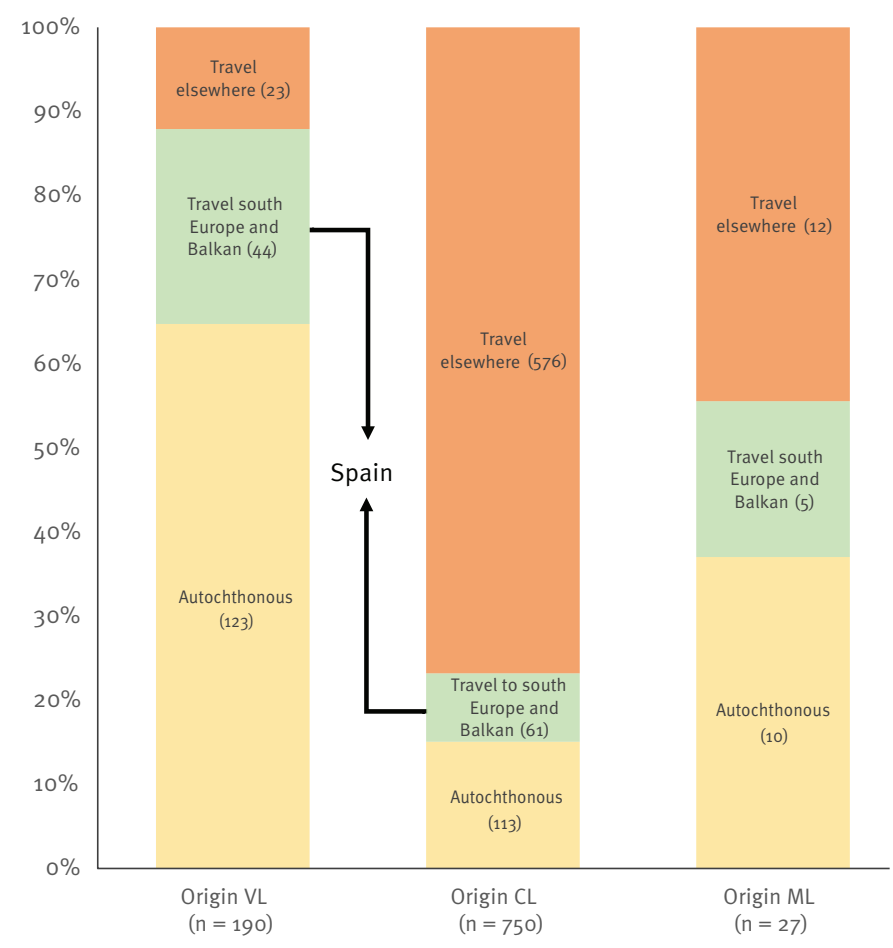

B. Diseases and species complexes from Europe

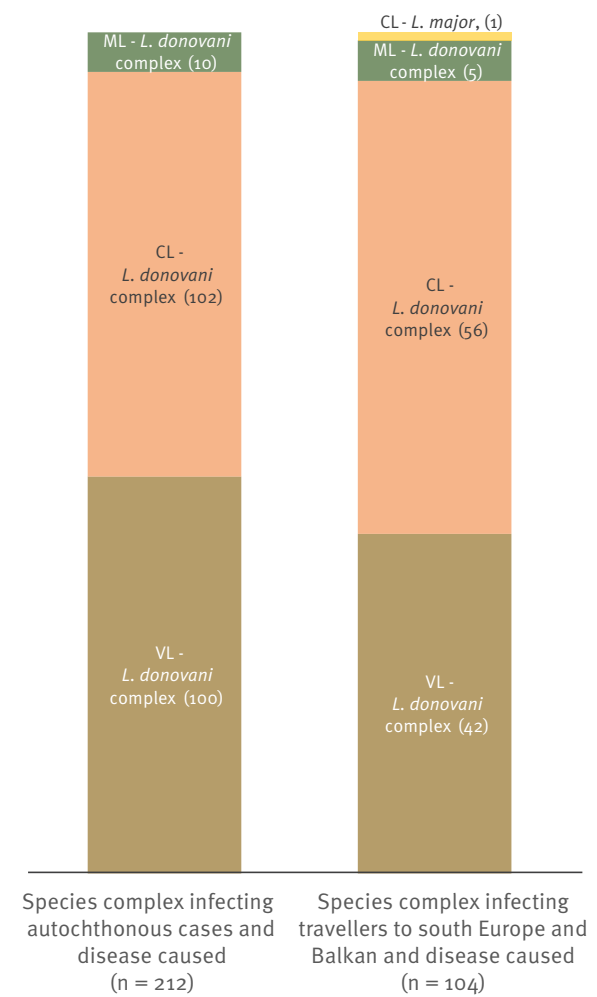

C. Import into Europe

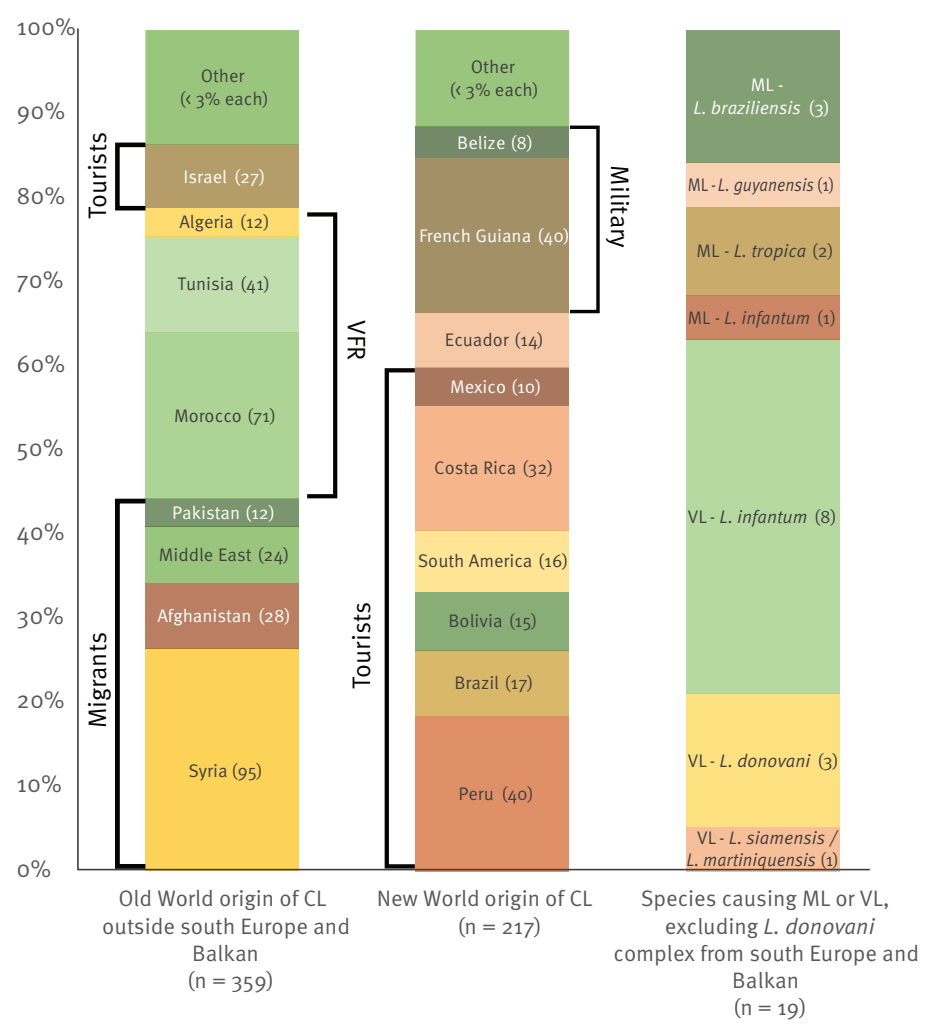

CL: cutaneous leishmaniasis; ML: mucosal leishmaniasis; VFR: cases who visited friends or relatives; VL: visceral leishmaniasis.

The absolute case numbers follow the categories in each bar graph. The variables indicated alongside the bars represent over $50 \%$ of the cases in the bar categories, e.g. Panel C. over $50 \%$ of Old World CL from each individual country/area specified (Afghanistan, Pakistan, Syria, Middle East) are seen in migrants. 
presumably infected. In both countries, autochthonous $C L$ is sporadically caused by the $L$. mexicana complex $[29,37,38]$. In the US, canine leishmaniasis from $L$. infantum is common [29], but no human infections are known and no canine cases have been described in Florida, US [39], the only state visited by the case.

In Afghanistan, CL from L. major and L. tropica infections is common [29], but CL cases from the $L$. donovani complex have been documented in travellers and soldiers $[40,41]$. In our dataset, two CL cases in migrants infected with the $L$. donovani complex were identified, one of which was typed to the species level as $L$. donovani. Further, we counted three noteworthy $C L$ cases caused by L. major, i.e. from Spain, Kazakhstan, and Ethiopia. Foci of $L$. major CL have been described in Kazakhstan, but the caseload is probably underreported [29]. In Ethiopia, the species was found in bats and sandflies, but was so far not identified in humans [42]. In Spain, including the Balearic Islands [29], not a single case of an L. major infection has been described, and $L$. infantum is known as the only aetiological agent of leishmaniasis. The case in our database concerns a tourist who returned with many sandfly bites from the Balearic island of Ibiza, and did not travel to any other known place endemic for leishmaniasis. The species typing was confirmed twice using HSP70 sequencing. In addition, a migrant from Eritrea was diagnosed with the $L$. tropica complex, probably the $L$. tropica species rather than $L$. aethiopica. Little information on the species in this country is known, even though both VL and $C L$ are present [29] and one report mentions an endemic $L$. aethiopica infection [43]. Finally, one $L$. siamensis / L. martiniquensis VL case in our dataset was described as originating from Guyana [44], but could have been infected elsewhere as this case visited Ghana and Caribbean Grenada, where this species was detected before [45]. Even though the aforementioned isolated cases do not imply local transmission in the respective countries, they may warrant species typing in patients returning from these areas.

\section{Limitations of the analysis}

The main limitation of our study is that the 15 participating centres are from 11 countries in western Europe and Scandinavia, which generally do not capture all medically attended leishmaniasis cases in their respective countries. We estimate that in each of the 11 countries we overall reported between 10 and $100 \%$ of all imported infections, which is a representative sample in terms of species distribution, geographic origin, and type of travel. As is the case for all travel-related diseases, when and where a patient was infected often cannot be determined with absolute certainty, which highlights the need to pool data from many institutes to confirm individual extraordinary observations. As many CL manifestations are self-healing or can be efficiently treated in a peripheral dermatology practice, our data collection probably missed relatively more $\mathrm{CL}$ compared with VL cases, as happens even in countries where the diseases are notifiable [10].
When comparing our data to those of the World Health Organization (WHO) Global Observatory [46] (consulted on 26 Jul 2021), we may have systematically under-reported the proportion of autochthonous infections. Of the countries that are represented in our dataset, leishmaniasis is endemic in France, Italy, Spain and Portugal. For these countries, partial WHO data are available for the period 2014-18. Of all VL cases in these countries, $9 \%(52 / 557)$ were imported, while this was $18 \%(23 / 126)$ in our dataset for the same reference period and countries. For $\mathrm{CL}$ and $\mathrm{ML}$ together, $59 \%(619 / 1046)$ was imported according to WHO, while this was $64 \%(177 / 278)$ in our analysis. Even though data from WHO are incomplete and also biased, underestimation of autochthonous infections in our analysis would not be surprising, as typically autochthonous diseases are treated in many medical facilities without referral to the specialised centres participating in this study. It is also in line with centres from France, Spain and Portugal reporting few autochthonous infections. An alternative explanation for the discrepancy would of course be that WHO systematically under-reported imported cases.

\section{Conclusions}

This study highlights the value of permanent monitoring of autochthonous and travel-related leishmaniasis cases in Europe. On one hand, such monitoring can confirm previous observations, on the other, surveillance can also draw attention to changes in the epidemiology of the diseases over time, or to endemic regions that have been under-studied and where awareness campaigns are needed. Cases imported into highincome countries, where effective species typing tools are available, are a rich source of information, provided that data from many medical centres are pooled to increase the number of observations. Resources like the WHO Global Health Observatory are excellent tools to implement such continuous surveillance. Since 2017, the Department of Control of Neglected Tropical Diseases of the WHO headquarters and the WHO Regional Office for Europe have provided financial and technical support to the European LeishMan network. With that support, databases have been aligned, allowing LeishMan centres to share their data of diagnosed leishmaniasis cases with WHO. This will improve surveillance of the epidemiology of the leishmaniases not only in Europe, but also in other parts of the world frequented by European citizens.

\section{MicroReact repository}

Supplemental data view in the MicroReact [23] platform: https://microreact.org/project/leishman-2014-2019

Surveillance of diagnosed leishmaniasis cases in LeishMan centres over the period 2014-19. Data are shown at the country level, except for five pie charts located at the exact same positions as in Figure 2. These represent cases who were infected in one of five endemic regions (Mediterranean, Sub-Saharan Africa, Middle East, Middle America, South 
America) but for whom the exact country of infection could not be reliably established. The pie chart shown between South America and Africa represents the cases that could not be linked to any of the aforementioned leishmaniasis endemic regions.

\section{Investigators}

LeishMan Surveillance Network members who contributed to this article (in addition to authors above): Emmanuel Bottieau, Jan Clerinx, Lieselotte Cnops, José Manuel Cristovão, JeanClaude Dujardin, Eleonora Fiorentino, Jean-Pierre Gangneux, Luigi Gradoni, Andreas K Lindner, Diana Lockwood, Stephen Walker, Aldo Scalone, Johan van Griensven

\section{Acknowledgements}

We thank the following colleagues for their input in parasite typing: Rahel Wampfler (Swiss Tropical and Public Health Institute, Basel, Switzerland); Federica Bergamini (Istituto Zooprofilattico Sperimentale della Lombardia e dell' EmiliaRomagna 'Bruno Ubertini', Brescia, Italy); Georgina Isak (The Public Health Agency of Sweden, Solna, Sweden); Ilse Maes and Isabel Micalessi (Institute of Tropical Medicine, Antwerp, Belgium); Christophe Ravel (University of Montpellier, Montpellier, France); and Cathrine Fladeby (Oslo University Hospital, Oslo, Norway).

Funding statement: No funding was obtained for this study. GVdA is supported by DGD-Belgium. PLC is supported by the University College London Hospitals Biomedical Research Centre.

\section{Conflict of interest}

None declared.

\section{Authors' contributions}

Data input and cleaning: Gert Van der Auwera, Leigh Davidsson, Pierre Buffet, Marie-Thérèse Ruf, Marina Gramiccia, Stefania Varani, Carmen Chicharro, Aldert Bart, Gundel Harms, Peter L Chiodini, Hanne Brekke, Florence Robert-Gangneux, Sofia Cortes, Jaco J Verweij, Alessandra Scarabello, Sara Karlsson Söbirk, Romain Guéry, Saskia van Henten, Trentina Di Muccio, Elena Carra, Pieter van Thiel, Martin Vandeputte, Valeria Gaspari, Johannes Blum, LeishMan Surveillance network. Data collection and analysis: Gert Van der Auwera. Publication writing: Gert Van der Auwera, Leigh Davidsson, Pierre Buffet, Marina Gramiccia, Stefania Varani, Carmen Chicharro, Aldert Bart, Gundel Harms, Hanne Brekke, Florence Robert-Gangneux, Sofia Cortes, Sara Karlsson Söbirk, Saskia van Henten, Trentina Di Muccio, Pieter van Thiel, Martin Vandeputte, Johannes Blum, LeishMan Surveillance network.

\section{References}

1. Burza S, Croft SL, Boelaert M. Leishmaniasis. Lancet. 2018;392(10151):951-70. https://doi.org/10.1016/S01406736(18)31204-2 PMID: 30126638

2. Dujardin JC, Campino L, Cañavate C, Dedet JP, Gradoni L, Soteriadou K, et al. Spread of vector-borne diseases and neglect of Leishmaniasis, Europe. Emerg Infect Dis. 2008;14(7):1013-8. https://doi.org/10.3201/eid1407.071589 PMID: 18598618

3. Ready PD. Leishmaniasis emergence in Europe. Euro Surveill. 2010;15(10):19505. https://doi.org/10.2807/ese.15.10.19505-en PMID: 20403308
4. Ehehalt U, Schunk M, Jensenius M, van Genderen PJ, GkraniaKlotsas E, Chappuis F, et al. Leishmaniasis acquired by travellers to endemic regions in Europe: a EuroTravNet multicentre study. Travel Med Infect Dis. 2014;12(2):167-72. https:// doi.org/10.1016/j.tmaid.2013.12.003 PMID: 24388687

5. Boggild AK, Caumes E, Grobusch MP, Schwartz E, Hynes NA, Libman M, et al. Cutaneous and mucocutaneous leishmaniasis in travellers and migrants: a 20 -year GeoSentinel Surveillance Network analysis. J Travel Med. 2019;26(8):tazo55. https://doi. org/10.1093/jtm/tazo55 PMID: 31553455

6. Gianchecchi E, Montomoli E. The enemy at home: leishmaniasis in the Mediterranean basin, Italy on the focus. Expert Rev Anti Infect Ther. 2020;18(6):563-77. https://doi.org/10.1080/147872 10.2020.1751611 PMID: 32249634

7. Blum J. LeishMan: harmonising diagnostic and clinical management of leishmaniasis in Europe. Euro Surveill. 2013;18(30):20538. PMID: 23929184

8. Gradoni L. Epidemiological surveillance of leishmaniasis in the European Union: operational and research challenges. Euro Surveill. 2013;18(30):20539. https://doi.org/10.2807/15607917.ES2013.18.30.20539 PMID: 23929176

9. World Health Organization. Leishmaniasis among neighbouring endemic countries in the Eastern Mediterranean, African and European regions. East Mediterr Health J. 2019;25(1):66-8. https://doi.org/10.26719/2019.25.1.66 PMID: 30919927

10. Tzani M, Barrasa A, Vakali A, Georgakopoulou T, Mellou K, Pervanidou D. Surveillance data for human leishmaniasis indicate the need for a sustainable action plan for its management and control, Greece, 2004 to 2018. Euro Surveill. 2021;26(18). https://doi.org/10.2807/1560-7917. ES.2021.26.18.2000159 PMID: 33960290

11. Schönian G, Mauricio I, Cupolillo E. Is it time to revise the nomenclature of Leishmania? Trends Parasitol. 2010;26(10):466-9. https://doi.org/10.1016/j.pt.2010.06.013 PMID: 20609626

12. Pothirat $\mathrm{T}$, Tantiworawit $\mathrm{A}$, Chaiwarith $\mathrm{R}$, Jariyapan $\mathrm{N}$, Wannasan A, Siriyasatien P, et al. First isolation of Leishmania from Northern Thailand: case report, identification as Leishmania martiniquensis and phylogenetic position within the Leishmania enriettii complex. PLoS Negl Trop Dis. 2014;8(12):e3339. https://doi.org/10.1371/journal. pntd.0003339 PMID: 25474647

13. Paranaiba LF, Pinheiro LJ, Torrecilhas AC, Macedo DH, Menezes-Neto A, Tafuri WL, et al. Leishmania enriettii (Muniz \& Medina, 1948): A highly diverse parasite is here to stay. PLoS Pathog. 2017;13(5):e1006303. https://doi.org/10.1371/journal. ppat.1006303 PMID: 28542526

14. Van der Auwera G, Dujardin JC. Species typing in dermal leishmaniasis. Clin Microbiol Rev. 2015;28(2):265-94. https:// doi.org/10.1128/CMR.00104-14 PMID: 25672782

15. Montalvo AM, Fraga J, Maes I, Dujardin JC, Van der Auwera $\mathrm{G}$. Three new sensitive and specific heat-shock protein 70 PCRs for global Leishmania species identification. Eur ] Clin Microbiol Infect Dis. 2012;31(7):1453-61. https://doi. org/10.1007/S10096-011-1463-Z PMID: 22083340

16. Van der Auwera G, Maes I, De Doncker S, Ravel C, Cnops L, Van Esbroeck M, et al. Heat-shock protein 70 gene sequencing for Leishmania species typing in European tropical infectious disease clinics. Euro Surveill. 2013;18(30):20543. https://doi. org/10.2807/1560-7917.ES2013.18.30.20543 PMID: 23929181

17. Fraga J, Montalvo AM, Maes L, Dujardin JC, Van der Auwera G. Hindll and Sdul digests of heat-shock protein 70 PCR for Leishmania typing. Diagn Microbiol Infect Dis. 2013;77(3):245 7. https://doi.org/10.1016/j.diagmicrobio.2013.07.023 PMID: 24050933

18. Schönian G, Nasereddin A, Dinse N, Schweynoch C, Schallig HD, Presber W, et al. PCR diagnosis and characterization of Leishmania in local and imported clinical samples. Diagn Microbiol Infect Dis. 2003;47(1):349-58. https://doi. org/10.1016/S0732-8893(03)00093-2 PMID: 12967749

19. Van der Auwera G, Ravel C, Verweij JJ, Bart A, Schönian G, Felger I. Evaluation of four single-locus markers for Leishmania species discrimination by sequencing. J Clin Microbiol. 2014;52(4):1098-104. https://doi.org/10.1128/JCM.02936-13 PMID: 24452158

20. Marfurt J, Nasereddin A, Niederwieser I, Jaffe CL, Beck HP, Felger I. Identification and differentiation of Leishmania species in clinical samples by PCR amplification of the miniexon sequence and subsequent restriction fragment length polymorphism analysis. J Clin Microbiol. 2003;41(7):3147-53. https://doi.org/10.1128/JCM.41.7.31473153.2003 PMID: 12843055

21. El Baidouri F, Diancourt L, Berry V, Chevenet F, Pratlong F, Marty P, et al. Genetic structure and evolution of the Leishmania genus in Africa and Eurasia: what does MLSA 
tell us. PLoS Negl Trop Dis. 2013;7(6):e2255. https://doi. org/10.1371/journal.pntd.0002255 PMID: 23785530

22. Minodier P, Piarroux R, Gambarelli F, Joblet C, Dumon H. Rapid identification of causative species in patients with Old World leishmaniasis. J Clin Microbiol. 1997;35(10):2551-5. https://doi. org/10.1128/jcm.35.10.2551-2555.1997 PMID: 9316906

23. Argimón S, Abudahab K, Goater RJE, Fedosejev A, Bhai J Glasner C, et al. Microreact: visualizing and sharing data for genomic epidemiology and phylogeography. Microb Genom. 2016;2(11):e000093. https://doi.org/10.1099/mgen.0.000093 PMID: 28348833

24. Elmahallawy EK, Alkhaldi AAM, Saleh AA. Host immune response against leishmaniasis and parasite persistence strategies: A review and assessment of recent research. Biomed Pharmacother. 2021;139:111671. https://doi. org/10.1016/j.biopha.2021.111671 PMID: 33957562

25. Snider H, Lezama-Davila C, Alexander J, Satoskar AR. Sex hormones and modulation of immunity against leishmaniasis. Neuroimmunomodulation. 2009;16(2):106-13. https://doi. org/10.1159/000180265 PMID: 19212130

26. Mansueto P, Seidita A, Vitale G, Cascio A. Leishmaniasis in travelers: a literature review. Travel Med Infect Dis. 2014;12(6 Pt A);563-81. https://doi.org/10.1016/j.tmaid.2014.09.007 PMID: 25287721

27. Statistics Explained. Tourism statistics - top destinations. Eurostat. [Accessed: 06 Jan 2022]. Available from: https:// ec.europa.eu/eurostat/statistics-explained/index. php?title=Tourism_statistics_-_top_destinations\#Spain_was_ the_top_foreign_destination_for_EU_residents_in_2019

28. United Nations Department of Economic and Social Affairs Population Division. International Migration 2019. New York: United Nations; 2019. Available from: https://www.un.org/ development/desa/pd/sites/www.un.org.development. desa.pd/files/files/documents/2020/Jan/un_2019 internationalmigration_highlights.pdf

29. Alvar J, Vélez ID, Bern C, Herrero M, Desjeux P, Cano J, et al. Leishmaniasis worldwide and global estimates of its incidence. PLoS One. 2012;7(5):e35671. https://doi.org/10.1371/journal. pone.0035671 PMID: 22693548

30. Herrera G, Barragán N, Luna N, Martínez D, De Martino F, Medina J, et al. An interactive database of Leishmania species distribution in the Americas. Sci Data. 2020;7(1):110. https:// doi.org/10.1038/S41597-020-0451-5 PMID: 32245983

31. Tateng AN, Kirstein OD, Ngouateu OB, Krüger A, von Stebut E, Maurer M, et al. First detection of Leishmania donovani in sand flies from Cameroon and its epidemiological implications. Trop Med Int Health. 2018;23(9):1014-21. https://doi.org/10.1111/ tmi.13123 PMID: 29947448

32. Kamara Bomba L, Saf'ianova VM, Goncharov DB, Emel'ianova LP. [The serological examination of the population for leishmaniasis and the detection of Leishmania in rodents in the Republic of Guinea]. Med Parazitol (Mosk). 1992; (2):42-6. PMID: 1435540

33. Kone AK, Niaré DS, Piarroux M, Izri A, Marty P, Laurens $\mathrm{MB}$, et al. Visceral Leishmaniasis in West Africa: Clinical Characteristics, Vectors, and Reservoirs. J Parasitol Res. 2019;2019:9282690. https://doi.org/10.1155/2019/9282690 PMID: 31565426

34. Kuhls K, Keilonat L, Ochsenreither S, Schaar M, Schweynoch C, Presber W, et al. Multilocus microsatellite typing (MLMT) reveals genetically isolated populations between and within the main endemic regions of visceral leishmaniasis. Microbes Infect. 2007;9(3):334-43. https://doi.org/10.1016/j. micinf.2006.12.009 PMID: 17307010

35. Jamjoom MB, Ashford RW, Bates PA, Chance ML, Kemp SJ, Watts PC, et al. Leishmania donovani is the only cause of visceral leishmaniasis in East Africa; previous descriptions of $L$. infantum and "L. archibaldi" from this region are a consequence of convergent evolution in the isoenzyme data. Parasitology. 2004;129(Pt 4):399-409. https://doi. org/10.1017/So031182004005955 PMID: 15521628

36. Franssen SU, Durrant C, Stark O, Moser B, Downing T, Imamura $\mathrm{H}$, et al. Global genome diversity of the Leishmania donovani complex. eLife. 2020;9:9. https://doi.org/10.7554/eLife.51243 PMID: 32209228

37. Yao C. Leishmania spp. and leishmaniasis on the Caribbean islands. Trans R Soc Trop Med Hyg. 2020;114(2):73-8. PMID: 31608958

38. Shaw J, Pratlong F, Floeter-Winter L, Ishikawa E, El Baidouri F, Ravel C, et al. Characterization of Leishmania (Leishmania) waltoni n.sp. (Kinetoplastida: Trypanosomatidae), the Parasite Responsible for Diffuse Cutaneous Leishmaniasis in the Dominican Republic. Am J Trop Med Hyg. 2015;93(3):552-8. https://doi.org/10.4269/ajtmh.14-0774 PMID: 26149864

39. Duprey ZH, Steurer FJ, Rooney JA, Kirchhoff LV, Jackson JE, Rowton ED, et al. Canine visceral leishmaniasis, United States and Canada, 2000-2003. Emerg Infect Dis. 2006;12(3):440-6. https://doi.org/10.3201/eid1203.050811 PMID: 16704782

40. Nagarajan P, Sloan BS. Isolated Cutaneous Leishmaniasis by Leishmania donovani in a Soldier Returning From Afghanistan. Am J Dermatopathol. 2015;37(7):591-2. https://doi. org/10.1097/DAD.0000000000000119 PMID: 25062262

41. Faulde MK, Erkens K, Dieterle R. Epidemiologie und Prophylaxe der Leishmaniasis in Nordafghanistan. [Epidemiology and prevention of leishmaniasis in northern Afghanistan]. Hautarzt. 2015;66(5):347-54. German. https://doi.org/10.1007/s00105015-3602-4 PMID: 25821066

42. van Henten S, Adriaensen W, Fikre H, Akuffo H, Diro E, Hailu A, et al. Cutaneous Leishmaniasis due to Leishmania aethiopica. EClinicalMedicine. 2019;6:69-81. https://doi.org/10.1016/j. eclinm.2018.12.009 PMID: 31193672

43. Zanger P, Kötter I, Raible A, Gelanew T, Schönian G, Kremsner PG. Case report: Successful treatment of cutaneous leishmaniasis caused by Leishmania aethiopica with liposomal amphothericin $B$ in an immunocompromised traveler returning from Eritrea. Am J Trop Med Hyg. 2011;84(5):692-4. https:// doi.org/10.4269/ajtmh.2011.10-0712 PMID: 21540377

44. Polley SD, Watson J, Chiodini PL, Lockwood DNJ. Visceral Leishmaniasis in traveler to Guyana caused by Leishmania siamensis, London, UK. Emerg Infect Dis. 2018;24(1):155-6. https://doi.org/10.3201/eid2401.161428 PMID: 29260661

45. Depaquit J, Kaltenbach ML, Gay F. Visceral Leishmaniasis in traveler to Guyana caused by Leishmania siamensis, London, UK. Emerg Infect Dis. 2018;24(8):1599-6oo. https://doi. org/10.3201/eid2408.172147 PMID: 30016253

46. World Health Organization (WHO). Leishmaniasis. Status of endemicity of cutaneous leishmaniasis: 2020. Geneva: WHO. [Accessed: 26 Jul 2021] Available from: https://apps.who.int/ neglected_diseases/ntddata/leishmaniasis/leishmaniasis.html

47. Rioux JA, Lanotte G, Serres E, Pratlong F, Bastien P, Perieres J. Taxonomy of Leishmania. Use of isoenzymes. Suggestions for a new classification. Ann Parasitol Hum Comp. 1990;65(3):111-25. https://doi.org/10.1051/parasite/1990653111 PMID: 2080829

\section{License, supplementary material and copyright}

This is an open-access article distributed under the terms of the Creative Commons Attribution (CC BY 4.0) Licence. You may share and adapt the material, but must give appropriate credit to the source, provide a link to the licence and indicate if changes were made.

Any supplementary material referenced in the article can be found in the online version.

This article is copyright of the authors or their affiliated institutions, 2022. 